\section{Questión}

Periodismo / Comunicación ISSN 1669-6581
- Av. $44 \mathrm{~N}^{\circ} 676,1^{\circ}$ piso

CP 1900 - La Plata - Argentina

(i) www.perio.unlp.edu.ar/question

Emerge el Estado

Cristian Secul Giusti

DOI: https://doi.org/10.24215/16696581e287

\title{
Emerge el Estado
}

\section{The Government emerges}

Cristian Secul Giusti / cristiansecul@gmail.com Licenciado en Comunicación Social y Doctor en Comunicación (UNLP). Docente Titular de la Tecnicatura en Comunicación Pública y Política de la Facultad de Periodismo y Comunicación Social. Investigador del Centro de Investigación en Lectura y Escritura (CILE).

Por fortuna, llegóse a tiempo de evitar la disolución del Estado gracias a la presencia política.

Juan Domingo Perón (1946)

La irrupción del COVID-19 generó conmoción a nivel mundial y produjo una serie de reflexiones en el universo académico, político y filosófico, a fin de entender el presente, ejercitar la crítica y también reconocer futuros posibles. De esa manera, investigadorxs e intelectuales de diferentes corrientes y perspectivas se hicieron eco de la tragedia pandémica e intentaron volcar sus ideas en crónicas, ensayos, charlas virtuales o artículos analíticos en un escenario de encierro masivo.

La primera etapa de evaluación fue confusa y vehemente, y estuvo signada por las visiones anglosajonas y eurocentristas de Giorgio Agamben, Slavoj Zizek, Franco "Bifo" Berardi, Byung Chul-Han, Alan Badiou y Judith Butler. Esas posturas iniciales -variadas y sostenidas por ópticas divergentes- sobrevolaron la lectura distópica y la revalorización marxista con el 
propósito de pensar una crisis capitalista o, quizás, un situación de resquebrajamiento del sistema. De este modo, las consideraciones circularon en los medios de comunicación tradicionales y se divulgaron ampliamente por las redes sociales, avanzando una tras otra, marcando un híbrido entre la teoría, la práctica y la catástrofe.

La siguiente oleada de análisis contuvo menor intensidad de circulación a causa de la saturación del aislamiento, y propició la aparición de voces aún más diversas ideológicamente. La mirada latinoamericana cobró relevancia en este período. $Y$ así, surgieron opiniones de pensadorxs europexs que aún no se habían manifestado, y también intelectuales de la región que plantearon tensiones con la noción apocalíptica de control social, el Estado panóptico y la dominacion casera de la tecnología.

La visión latinoamericana continúa vigente, y no se muestra a ciegas, sino atiende los cambios de paradigma e incluye a la virtualidad como un factor de complejidad. Aún así, su marco de enunciación posiciona una idea de revalorización del Estado y de la politicidad democrática. En la Argentina, de hecho, el papel de la función estatal y su participación en el cuidado general sirven para contraponer los postulados economicistas y sociales de la avanzada neoliberal y de la liberación del mercado.

La revalorización estatal

En la reunión vertiginosa de opiniones, el presente pandémico es leído desde aristas opuestas y también analizado con mayor o menor tino. En el caso de la propuesta europea o anglosajona, se advierte una voluntad de categorización y de definición sobre la marcha, a fin de querer superar el ardor y detectar un fenómeno lo más rápido posible. Más aún, también se busca desmontar el horizonte y destacar el futuro más próximo, tilado de agónico y voraz.

Esa lectura nos permite señalar distancias de contexto y de apreciación, más allá de que el COVID-19 nos ubique en una zona de amenaza constante. En ese sentido, las nociones de lazo social, politicidad, distribución estatal, resistencia o aislamiento se vuelven palabras clave que forjan distintos destinos en las elucubraciones.

Mientras que en Europa (y quizás parte de Asia) hay una mirada tensionada sobre la participación del Estado (salvo en Alemania o los países nórdicos), en parte de América Latina se evidencia el protagonismo fundamental de los liderazgos presidenciales y una distribución institucional que coloca en crisis a los paladines del liberalismo económico y pro-mercado. 
Esto último no quiere decir que haya inocencia o confianza plena en el Estado (hay notables diferencias entre Brasil y la Argentina, o Ecuador y Uruguay, por ejemplo). En nuestro país, por ejemplo, se evidencia una confirmación diferente de la concepción del Estado que augura una perspectiva más preocupada que apocalíptica, y más cercana a una respuesta de supervivencia ante la crisis, con tradiciones de organización diferente y con una estructura que incluye distintas condiciones.

Al respecto, coronavirus es una pandemia expansiva que se configura como significante vacío para cada gobierno y cada sociedad. Las administraciones políticas de la región le asignan sentido según sus propios contextos de enunciación, sus antecedentes históricos y sus diversxs destinatarixs. Por su parte, los medios de comunicación masiva, sumamente vinculados a los estratos del poder real y los discursos hegemónicos del libre mercado, se suman tibiamente a una narrativa de preservación estatal y también arrojan nociones que destacan muy superficialmente el daño de la mirada privatista y neoliberal sobre la salud, la educación y la organización del trabajo.

En esa trama, la idea del Estado cuidador no es una idea que se celebra a tientas, ni tampoco se la toma sin marcar tensiones u opacidades. Sin embargo, como señala Horacio González (2020):

Es cierto que tampoco estamos ante una dictadura técnico-médica-policialdigital, como algunos proponen pensar a China o a Corea del Sur, donde cada sujeto ya reviste la condición de un dato digital descomponible -como el coronavirus- en sus proteínas y sus capas de grasas, a punto que se sepa a cada instante de cada cuerpo "su temperatura corporal, su propensión a infectarse".

A partir de la revalorización estatal (como eje dirigente del bienestar y el resguardo) y la política como experiencia crucial para general lazos colaborativos y solidarios, es posible pensar modos de enfrentar el futuro mercantil, numerado, controlador. En contraposición con las nociones apocalípticas, la actualidad pandémica es, además de todo, una posibilidad de construir cuidados comunitarios y una organización que posibilite reafirmar luchas democráticas. Así, como manifiesta María Pía López (2020), podría concretarse "un impulso que lleva más allá de la preservación de la vida tal cual existe (y que está amenazada por el hambre y la enfermedad), para ir hacia la apuesta de una vida que valga la pena de ser vivida". 
Álvaro García Linera (2020), por su parte, focaliza en la situación actual de la globalización, sostiene que no hay respuesta globalizada a un drama global y sentencia que el discurso político de esas corrientes también se encuentra en crisis:

Resulta grotesco ver a los profetas del libre comercio y del "Estado mínimo " que ayer exigían derribar las fronteras nacionales y deshacerse de los "costosos" sistemas de derechos sociales (salud, educación, jubilación), salir ahora a aplaudir el cierre profiláctico de las fronteras y exigirle al Estado medidas más drásticas para atender a los ciudadanos y reactivar las economías nacionales.

Al respecto, la importancia de la revalorización del Estado en la Argentina no se da únicamente en el marco discursivo, también se refuerza en su función social-protectiva y económicofinanciera. Indudablemente, esto no solo genera una fractura en la retórica de los mercados globales y sus defensorxs a ultranza, también recalca la necesaria persistencia de los Estados y la preservación de la salud pública como núcleos fundamentales de sociabilidad y protección.

Hasta ahora

La cohabitación de voces intelectuales en este escenario de convulsión mundial permite encontrar distancias con las miradas europeas, y revalorizar también la propia mirada regional, tan característica y atravesada por luchas propias y demandas que han constituido lazos particulares y espectros singulares.

En ese sentir del encierro (programado, remarcado, habilitado para el cuidado general) proliferan subjetividades y también distinciones que nos empujan a leer y escuchar ideas desarrolladas por fuera de nuestro continente, pero también analizar a la luz de nuestras conquistas y/o derrotas. Sobre este punto, son los Estados nacionales los que afrontan los gastos, las desidias del neoliberalismo y los huecos profundos de los capitales privados que se ahuyentan a la hora de afrontar un período de pánico.

El devenir de nuestro "yendo de la cama al living latinoamericano" integra una voz arraigada que repone historicidad y consolida una disputa de sentidos políticos, sociales y económicos que no debe perderse de vista. Si el planeta está patas para arriba, los papeles caídos en el piso y las rutas totalmente cambiadas, mejor seguir el GPS del Estado presente, la política 
como regulación de la vida cotidiana, la democracia como resguardo de los derechos y la reflexión latinoamericanista como horizonte.

La pandemia acosa, la potencialidad estatal crece y el capitalismo financiero sostiene su enriquecimiento a costa de las vidas despojadas y el blindaje sistémico. Es una lucha desigual, incluso desesperada contra el salvajismo, pero también una situación de posicionamiento para que la política empuje el tren de la justicia social, organice las cualidades del pueblo y resguarde la salud pública en un escenario volcánico.

Bibliografía

García Linera, A. (2020). "Conocimiento Social en Tiempos de Horizontes Colapsados". En Clase inaugural del Instituto de Altos Estudios Sociales de la Universidad Nacional de San Martín. Buenos Aires, Argentina. Recuperado de https://primerageneracion.net/2020/04/06/losmercados-financieros-no-curan-enfermedades-globales/

González, H. (2020). "La inmovilización". En Lobo Suelto. Buenos Aires, Argentina. Recuperado de http://lobosuelto.com/la-inmovilizacion-horacio-gonzalez/

López, M. P. (2020). "La vida en cuestión". En La Fiebre. Pensamiento contemporáneo en tiempo de pandemia. Buenos Aires, Argentina. Recuperado de http://www.agenciapacourondo.com.ar/debates/fiebre-la-version-argentina-de-sopa-de-wuhan Secul Giusti, C. (2020). "Yendo de la cama al living: entre el Estado y el apocalipsis". En Revista Primera Generación. Buenos Aires, Argentina. Recuperado de http://sedici.unlp.edu.ar/bitstream/handle/10915/93619/Documento_completo.pdfPDFA.pdf? sequence $=1$ \&isAllowed $=y$ 